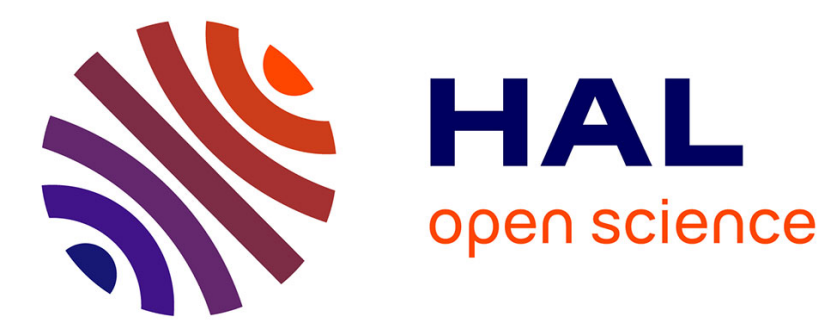

\title{
Difference in mechanical and energy cost between highly, well, and nontrained runners
}

Jean Slawinski, Véronique L Billat

\section{To cite this version:}

Jean Slawinski, Véronique L Billat. Difference in mechanical and energy cost between highly, well, and nontrained runners. Medicine and Science in Sports and Exercise, 2004, 36 (8), pp.1440-1446. 10.1249/01.MSS.0000135785.68760.96 . hal-01696976

\section{HAL Id: hal-01696976 https: / hal-insep.archives-ouvertes.fr/hal-01696976}

Submitted on 30 Jan 2018

HAL is a multi-disciplinary open access archive for the deposit and dissemination of scientific research documents, whether they are published or not. The documents may come from teaching and research institutions in France or abroad, or from public or private research centers.
L'archive ouverte pluridisciplinaire HAL, est destinée au dépôt et à la diffusion de documents scientifiques de niveau recherche, publiés ou non, émanant des établissements d'enseignement et de recherche français ou étrangers, des laboratoires publics ou privés. 
Difference in mechanical and energy cost between highly, well and non trained runners.

SLAWINSKI JS ${ }^{1}$, BILLAT VL ${ }^{1}$, FACSM

1 Department STAPS, UFRSFA University d'Evry-Val d'Essonne, Batiment des Sciences Boulevard François Mitterand 91025 EVRY cedex, France.

Med. Sci. Sports Exerc., Vol. 36, No. 8, pp. 1440-1446, 2004.

Corresponding author: Slawinski Jean,

Adress for correspondance: Centre de Médecine du Sport CCAS, 2 Avenue

$$
\begin{aligned}
& \text { Richerand, 75010 Paris, France. } \\
& \text { Phone : }+33.1 .42 .02 .08 .18 \\
& \text { Fax : +33.1.42.39.20.83 } \\
& \text { E-mail : jeanslawinski@yahoo.fr }
\end{aligned}
$$

Running title: Training and biomechanics of running. 


\begin{abstract}
Introduction: Recently it has been shown that endurance training decreases the variability in stride rate. This decrease would lead to a reduction in the mechanical and the energy cost of running. Purpose: This study therefore aims to compare the mechanical and the energy cost of running according to the training status of the runner (highly, well and non trained endurance runners). Methods: The kinetic, potential and internal mechanical costs $\left(\mathrm{C}_{\mathrm{ke}}, \mathrm{C}_{\mathrm{pe}}\right.$ and $\left.\mathrm{C}_{\mathrm{int}}\right)$ were measured with a $3 \mathrm{D}$ motion analysis system (ANIMAN3D). The energy cost of running (C), was measured from pulmonary gas exchange using a breath by breath portable gas analyser (Cosmed $\mathrm{K} 4 \mathrm{~b}^{2}$, Roma, Italy). All the parameters were measured on track, for a speed of $4.84 \pm$ $0.36 \mathrm{~m} \cdot \mathrm{s}^{-1}$. Results: Highly trained runners did not exhibit significantly lower C compared to well or non trained runners $\left(4.46 \pm 0.38 ; 4.33 \pm 0.32 ; 4.46 \pm 0.46{\mathrm{~J} . \mathrm{kg}^{-}}^{-}\right.$ ${ }^{1} . \mathrm{m}^{-1}$, respectively; $\left.\mathrm{p}=0.75\right)$. However, $\mathrm{C}_{\mathrm{pe}}$ was significantly lower in highly and well trained runners compared to non trained runners $(0.43 \pm 0.07 ; 0.45 \pm 0.05 ; 0.54 \pm 0.08$ $\mathrm{J} . \mathrm{kg}^{-1} \cdot \mathrm{m}^{-1}$, respectively; $\mathrm{p}<0.05$ ). In contrast, $\mathrm{C}_{\mathrm{int}}$ was significantly higher in highly trained runners compared to well and non trained runners (respectively $0.80 \pm 0.12$; $\left.0.60 \pm 0.09 ; 0.59 \pm 0.10 \mathrm{~J} \cdot \mathrm{kg}^{-1} \cdot \mathrm{m}^{-1} ; \mathrm{p}<0.05\right)$. Conclusion: Although there is a significant difference in $C_{p e}$ and in $C_{i n t}$ between runners of various training status, there is no difference in $C$. Differences in $C_{p e}$ and $C_{\text {int }}$ may be associated with the same self-optimizing mechanism which contributes to a reduction in the impact loads during the initial portion of the support phase of the stride.
\end{abstract}

Keys-words: oxygen uptake, biomechanics, training, running. 


\section{Introduction}

Paragraph Number 1

In middle and long distance events, maximal performance depends on the optimisation of aerobic and biomechanical factors. The energy cost of running, defined as the amount of energy spent per unit of distance (18), reflects the sum of both aerobic and biomechanical demands. In aerobic conditions, the metabolic power can be estimated by oxygen uptake $\left(\dot{\mathrm{VO}}_{2}\right)$. Among long distance runners with comparable maximal oxygen uptake $\left(\dot{\mathrm{V}}_{2 \text { max }}\right.$ ), the energy cost of running $(\mathrm{C})$ is a discriminating parameter in endurance performance (18). While various factors have been found to affect $\mathrm{C}$ (28), little is known about training effect on C. It seems that the use of interval training sessions over a long period (14 weeks to 5 years) brings about a decrease in C $(5,31,33)$. However, many studies did not find any link between these parameters, so the reasons for $\mathrm{C}$ improvement with training are not well known.

\section{Paragraph Number 2}

Biomechanical parameters have been identified as factors that could influence C. Williams and Cavanagh (37) demonstrated that 54\% of the inter-individual variability of $\mathrm{C}$ could be explained by kinematic variables. These authors demonstrated that the more economical runners possess a characteristic running style. They present numerous differences in kinematic variables and some of them are correlated with $\mathrm{C}$. The mechanical cost of the movements of the centre of mass has also been identified as a potential biomechanical parameter that could explain the inter-individual variability in $C[8,9]$. Indeed, $C$ represents the energy used by the active muscle to produce mechanical work. Thus, the inter-individual differences in $\mathrm{C}$ have to be related to the variation in mechanical energies associated with the movement of the different segments of the body during running. Some studies have found a significant 
relationship between the inter-individual differences in $\mathrm{C}$ and the variation in mechanical energies of the centre of mass during running $[8,9]$. Recently, Borrani et al. [7] suggest that the modification of $\mathrm{C}$ could be related to a modification of an index of the internal cost. Therefore, in order to understand why there are significant differences in $\mathrm{C}$ among runners of different training status, there is a need to compare kinetic, potential, and internal energies indices in addition to the overall energy cost. However, effects of endurance training on these biomechanical factors have been poorly investigated. Indeed, most of the current studies have focused on the effect of training on simple mechanical stride parameters such as stride rate or stride length (1, 37). More recently, a study performed in our laboratory (31), showed that endurance training leads to a decrease in the stride rate variability. It has been hypothesised that the decrease of the stride rate variability would induce a decrease in the mechanical cost of running by reducing the amplitude of movement of the centre of mass. However, direct measurements of the effect of the training on kinetics, potential and internal mechanical cost $\left(\mathrm{C}_{\mathrm{ke}}, \mathrm{C}_{\mathrm{pe}}\right.$ and $\left.\mathrm{C}_{\mathrm{int}}\right)$ are not available.

\section{Paragraph Number 3}

Therefore, this study aims to examine the differences of mechanical and energy cost for groups of runners with different levels of training. The hypothesis being that the lower energy cost in highly trained runners would be associated with a lower mechanical cost. In order to test this hypothesis, $\mathrm{C}, \mathrm{C}_{\mathrm{ke}}, \mathrm{C}_{\mathrm{pe}}$ and $\mathrm{C}_{\mathrm{int}}$ were measured in three populations with different training status. 


\section{METHODS}

\section{Paragraph Number 4}

\section{Subjects}

Three groups took part of the experimental protocol:

- Seven highly trained ( 3 men and 4 women) runners $(170 \pm 7 \mathrm{~cm} ; 55.7 \pm$ $9.2 \mathrm{~kg}$ ), who were members of the national French marathon team (mean performance $2 \mathrm{~h} 27 \min 16 \mathrm{~s} \pm 11 \min 02 \mathrm{~s}$ ). They train about 12 times a week between 60 and $100 \%$ of the maximal oxygen uptake $\left(\dot{\mathrm{VO}}_{2 \max }\right)$.

- Eight well trained runners $(169 \pm 9 \mathrm{~cm} ; 57.2 \pm 7.7 \mathrm{~kg})$, who have already participated to a national competition. They train about 5 times a week between 60 and $100 \%$ of $\dot{\mathrm{VO}}{ }_{2 \max }$.

- Six non-trained runners $(175 \pm 5 \mathrm{~cm} ; 68.8 \pm 6.5 \mathrm{~kg})$, physical education students who were occasional runners. They train about 2 times a week at long slow distance running $\left(60 \%\right.$ of $\left.\dot{\mathrm{VO}}_{2 \max }\right)$.

All subjects were informed of risks and stress associated with the experimental protocol and gave a written voluntary informed consent in accordance with the guidelines of the hospital of Paris $\mathrm{S}^{\mathrm{t}}$ Louis.

Paragraph Number 5

\section{Experimental design}

The energy cost of running (C), the kinetic and potential mechanical cost associated with the movements of the centre of mass $\left(\mathrm{C}_{\mathrm{ke}}\right.$ and $\left.\mathrm{C}_{\mathrm{pe}}\right)$, and the internal mechanical cost associated with the movements of the body's segments around the centre of mass $\left(C_{\text {int }}\right)$ were measured during a constant load running exercise $\left(\mathrm{V}=4.84 \pm 0.36 \mathrm{~m} \cdot \mathrm{s}^{-1}\right)$. 
The energy cost of running (C), the kinetic and potential mechanical cost associated with the movements of the centre of mass $\left(\mathrm{C}_{\mathrm{ke}}\right.$ and $\left.\mathrm{C}_{\mathrm{pe}}\right)$, and the internal mechanical cost associated with the movements of the body's segments around the centre of mass $\left(C_{\text {int }}\right)$ were measured during a constant load running exercise $\left(V=4.84 \pm 0.36 \mathrm{~m} \cdot \mathrm{s}^{-1}\right)$.

Highly trained runners carried out a 30 minute run on a level road at a constant velocity (table 1). The velocity was set at the average velocity sustained during their best marathon race. Runners followed a pacing cyclist traveling at the required velocity. The cyclist was equipped with a speedometer with a speed precision of \pm 0.1 $\mathrm{km} \cdot \mathrm{h}^{-1}$. This protocol allowed us to measure $\mathrm{C}, \mathrm{C}_{\mathrm{ke}}, \mathrm{C}_{\mathrm{pe}}, \mathrm{C}_{\mathrm{int}}$ and to estimate $\dot{\mathrm{VO}}_{2 \max }$ and the velocity associated with the achievement of $\dot{\mathrm{V}}{ }_{2 \max }\left(\mathrm{v} \dot{\mathrm{V}}{ }_{2 \max }\right)$.

Table 1: Characteristics of the different populations (highly, well and non-trained): maximal oxygen uptake $\left(\dot{\mathrm{VO}}_{2 \max }\right)$, the speed associated to $\dot{\mathrm{V}} \mathrm{2}_{2 \max }\left(\mathrm{v} \dot{\mathrm{V}} \mathrm{O}_{2 \max }\right)$ and the speed of the constant load exercises.

\begin{tabular}{|c|c|c|c|c|}
\hline & $\begin{array}{l}\text { Highly trained } \\
( \pm S D)\end{array}$ & $\begin{array}{c}\text { Well trained } \\
( \pm S D)\end{array}$ & $\begin{array}{c}\text { Non-trained } \\
( \pm S D)\end{array}$ & $A N O V A$ \\
\hline Height $(\mathrm{cm})$ & $169 \pm 9$ & $171 \pm 7$ & $175 \pm 5$ & 0.27 \\
\hline Weight (kg) & $55.7 \pm 9.2$ & $57.2 \pm 7.7$ & $68.8 \pm 6.5^{\dagger \S}$ & 0.02 \\
\hline$v \dot{V} O_{2 \max }\left(m \cdot s^{-1}\right)$ & $\begin{array}{l}\quad 6.12 \pm 0.44 \\
\text { (estimated) }\end{array}$ & $\begin{array}{l}5.30 \pm 0.30^{\dagger} \\
\text { (measured) }\end{array}$ & $\begin{array}{l}4.79 \pm 0.33^{\dagger \S} \\
\text { (measured) }\end{array}$ & $\leq 0.01$ \\
\hline$\dot{\mathrm{V}} \mathrm{O}_{2 \max }\left(\mathrm{ml} \cdot \mathrm{kg}^{-1} \cdot \mathrm{min}^{-1}\right)$ & $\begin{array}{l}\quad 79.0 \pm 7.3 \\
\text { (estimated) }\end{array}$ & $\begin{array}{c}65.7 \pm 6.1^{\dagger} \\
\text { (measured) }\end{array}$ & $\begin{array}{c}57.2 \pm 7.7^{\dagger \S} \\
\text { (measured) }\end{array}$ & $\leq 0.01$ \\
\hline Running speed $\left(m . s^{-1}\right)$ & $4.87 \pm 0.42$ & $4.96 \pm 0.31$ & $4.65 \pm 0.32$ & 0.28 \\
\hline
\end{tabular}

${ }^{\dagger}$ Significantly different from highly trained runner $(\mathrm{p} \leq 0.05)$.

${ }^{\S}$ Significantly different from well trained runner $(\mathrm{p} \leq 0.05)$.

\section{Paragraph Number 6}

The well trained and the non trained subjects performed two exhaustive exercises. The first exercise was an incremental test allowing $\dot{\mathrm{VO}}_{2 \max }, \mathrm{v} \dot{\mathrm{V}}{ }_{2 \max }$ and the velocity at 
the lactate threshold (vLT) to be determined. The running speed of this test was progressively increased from $12 \mathrm{~km} \cdot \mathrm{h}^{-1}$ to exhaustion. The velocity increments between the stages ( 3 min duration) were set at $1 \mathrm{~km} \cdot \mathrm{h}^{-1}$. All stages were followed by a 30-s period of rest. During this period, a fingertip capillary blood sample was collected in order to calculate the energetic equivalent of lactate (EEL). The second exercise was a test to exhaustion at the velocity corresponding to $50 \%$ of the work rate difference between $\mathrm{vLT}$ and $\mathrm{v} \dot{\mathrm{V}} \mathrm{O}_{2 \max }(\mathrm{v} \Delta 50)$ for the well trained runners. For the non trained runner, the velocity of the exercise was set at $95 \%$ of $\mathrm{v} \dot{\mathrm{VO}}_{2 \max } . \mathrm{C}, \mathrm{C}_{\mathrm{ke}}, \mathrm{C}_{\mathrm{pe}}$ and $\mathrm{C}_{\mathrm{int}}$ were determined during the last minute of the exercise. All test sessions were completed on a 400-m covered synthetic track. Throughout the tests, the subjects adopted the required velocity using an audio rhythm which gave the time to cover 25m. Visual marks were set at 25-m intervals along the track (inside the first lane).

\section{Paragraph Number 7}

Energy cost measurement (C).

Throughout the constant velocity exercises, the respiratory and pulmonary gas exchange variables were measured using a breath-by-breath portable gas analyzer (Cosmed $\mathrm{K}_{4} \mathrm{~b}^{2}$, Roma, Italy (26)). Before each test, $\mathrm{O}_{2}$ and $\mathrm{CO}_{2}$ analyser were calibrated using ambient air and sample gas references. The flowmeter was calibrated with a 3-1 syringe (Quinton instruments, Seattle, USA). Blood lactate concentration was measured for the three groups of runners, before and after the constant velocity exercises.

\section{Paragraph Number 8}

The breath-by-breath oxygen uptake data were reduced to 5-s stationary averages. These data were then smoothed, using a 3-step average filter, to reduce the noise, so as to enhance the underlying characteristics. These data were finally fitted to 
mathematical exponential models (2) using an iterative nonlinear regression on Sigma Plot software (SPSS, Chicago, IL, USA). A single-exponential model (eq. 1) and a double-exponential models were used, comprising two exponential terms which start at two distinct time delays from the onset of exercise (eq. 2). The Fisher test, which was performed by the Sigma Plot software, was used to choose the model for which the fit was associated with the highest $F$ value (2).

$$
\begin{aligned}
\dot{\mathrm{VO}_{2}}(\mathrm{t})= & \mathrm{A}_{0}+\mathrm{A} 1 \times\left(1-\mathrm{e}^{-(\mathrm{t}-\mathrm{TD} 1) / \tau_{1}}\right) \times \mathrm{U}_{1} \\
& (\text { linear and fast component }) \\
+ & \mathrm{A} 2 \times\left(1-\mathrm{e}^{-(\mathrm{t}-\mathrm{TD} 2) / \tau_{2}}\right) \times \mathrm{U}_{2} \\
& (\text { slow component })
\end{aligned}
$$

With:

$\mathrm{A}_{0}$ : the basal metabolic rate $\left(\mathrm{ml} \cdot \mathrm{min}^{-1}\right)$.

A1 and A2 : the asymptotic amplitudes for the exponential terms $\left(\mathrm{ml} \cdot \mathrm{min}^{-1}\right)$.

$\tau_{1}$ and $\tau_{2}:$ the time constants (s).

TD1 and TD2: the time delay from the onset of exercise (s).

C was expressed in $\mathrm{J}_{\mathrm{kg}} \mathrm{kg}^{-1} \cdot \mathrm{m}^{-1}$ and computed from the following equation:

$$
\mathrm{C}\left(\mathrm{J} \cdot \mathrm{kg}^{-1} \cdot \mathrm{m}^{-1}\right)=\dot{\mathrm{V}} \mathrm{O}_{2}(\mathrm{t}) \times \mathrm{E}_{\mathrm{O}_{2}} \times \mathrm{V}^{-1} \times \mathrm{M}^{-1}
$$

To calculate the energy expenditure, an energy equivalent of oxygen $\left(\mathrm{E}_{\mathrm{O}_{2}}\right)$ was applied. $\mathrm{E}_{\mathrm{O}_{2}}$ depends on the respiratory quotient. For elite runners $\mathrm{E}_{\mathrm{O}_{2}}$ was equal to 20.9 J. $\mathrm{mlO}_{2}^{-1}$, for the other runners $\mathrm{E}_{\mathrm{O}_{2}}$ was equal to $21.3 \mathrm{~J} . \mathrm{mlO}_{2}^{-1}$. "V" is the running speed during the test (expressed in $\mathrm{m} \cdot \mathrm{min}^{-1}$ ) and "M" is the subject's mass. EEL was equal to $3 \mathrm{mlO}_{2} \cdot \mathrm{kg}^{-1} \cdot \mathrm{mmol}^{-1} \cdot \mathrm{l}^{-1}$ (9), this value was added to $C$ in order to estimate the contribution of the anaerobic pathway $(C+E E L)$. 
Paragraph Number 9

$\dot{V} O_{2 \max }$ and $v \dot{V} O_{2 \max }$ measurement.

Well trained and non trained runners performed an incremental exercise, so $\dot{\mathrm{VO}}_{2 \max }$ and $\mathrm{v} \dot{\mathrm{V}}{ }_{2 \max }$ were directly measured from gas exchanges. The elite runners did not participate in the incremental exercise, therefore $\dot{\mathrm{V}} \mathrm{O}_{2 \max }$ and $\mathrm{v} \dot{\mathrm{V}}{ }_{2 \max }$ were estimated from the maximal fraction of $\dot{\mathrm{V}}{ }_{2 \max }$ that can be maintained throughout the duration of the effort ( $\mathrm{F}$ expressed in \%). The quantification of $\mathrm{F}$ follows the equation (17):

$$
\mathrm{F}=0.94-10^{-3} \times \mathrm{T}
$$

Where " $T$ " is the best performance time ( $\mathrm{min}$ ) achieved in an endurance race. The intensity of the 30 min test was set at the average velocity sustained during the best marathon race of each runner. Therefore, $F$ can be deduced from the best time achieved during the best marathon. From $\mathrm{F}$ and the oxygen uptake $\dot{\mathrm{VO}}_{2}(\mathrm{t})$ measured during the 30 min test, it was easy to calculate $\dot{\mathrm{V}}{ }_{2 \max }$ and $\mathrm{v} \dot{\mathrm{V}}{ }_{2 \max }$ :

$$
\begin{aligned}
& \dot{\mathrm{V}} \mathrm{O}_{2 \max }\left(\mathrm{ml} \mathrm{kg}^{-1} \cdot \mathrm{min}^{-1}\right)=\frac{\dot{\mathrm{VO}}(\mathrm{t})}{\mathrm{F}} \times \mathrm{M}^{-1} \\
& \mathrm{v} \dot{\mathrm{V}} \mathrm{O}_{2 \max }\left(\mathrm{m} \cdot \mathrm{min}^{-1}\right)=\frac{\dot{\mathrm{V}} \mathrm{O}_{2 \max }}{\dot{\mathrm{VO}} \mathrm{O}_{2}(\mathrm{t}) \times \mathrm{V}^{-1} \times \mathrm{M}^{-1}}
\end{aligned}
$$

Where "V" is the average velocity of the 30 min test, (expressed in $\mathrm{m} \cdot \mathrm{min}^{-1}$ ) and "M" is the subject's mass.

Paragraph Number 10

\section{Mechanical cost measurement}

During the constant load exercise, runners were filmed by a digital video camera (Sony, Japan, TRV 900) using a sampling frequency of $25 \mathrm{~Hz}$. Two consecutive steps 
were analysed at the end of the exercise (figure 1). The video sequences were digitised on a computer using a video card (Perception Video Recorder, Digital System Inc.), and then transformed into a set of bitmap pictures. The parametric trajectories of the anatomical points of the runner were determined using a motion analysis system, ANIMAN3D (34). This system uses a numerical manikin "MAN3D" (figure 2). The morphology of this numerical manikin integrates inertial properties of the different segments. The morphology of this numerical manikin could be adjusted to each runner from their height and weight. This model measures the 3D positions of the body, during running. In the present work, the lateral displacements of the different centres of masses have not been directly measured because only one camera was used. All the trajectories of the different centres of mass (segments and body centre of mass) were smoothed using a polynomial method in order to obtain by derivation the speed displacement of the different centres of mass. Variations of potential and kinetic energies ( $\Delta \mathrm{E}_{\mathrm{pe}}$ and $\Delta \mathrm{E}_{\mathrm{ke}}$ respectively) were then calculated (in joules).

$$
\begin{aligned}
& \Delta \mathrm{E}_{\mathrm{pe}}=\mathrm{M} \times \mathrm{g} \times\left(\mathrm{H}_{\text {max }}-\mathrm{H}_{\text {min }}\right) \\
& \Delta \mathrm{E}_{\mathrm{ke}}=\frac{1}{2} \mathrm{M} \times\left(\mathrm{V}_{\text {max }}^{2}-\mathrm{V}_{\text {min }}^{2}\right)
\end{aligned}
$$

"M" is the body mass $(\mathrm{kg})$, " $\mathrm{g}$ " is the gravitational acceleration $\left(9.81 \mathrm{~m} \cdot \mathrm{s}^{-2}\right)$, " $\mathrm{H}_{\max }$ and $\mathrm{H}_{\text {min }}$ " are the maximal and minimal heights of the body centre of mass $(\mathrm{CM})$ during one step (m). " $\mathrm{V}_{\max }$ and $\mathrm{V}_{\min }$ " are the maximal and minimal horizontal velocities of the CM during one step $\left(\mathrm{m} . \mathrm{s}^{-1}\right)$.

\section{Paragraph Number 11}

The variation of the internal energy $\left(\Delta \mathrm{E}_{\text {int }}\right)$ represents the variations in mechanical energies associated with the movement of the different segments of the body around 
the CM. The present model used in this work (figure 2) is composed of 17 different segments. The variation of internal energy $\left(\Delta \mathrm{E}_{\mathrm{int}}\right)$ is calculated,

$$
\Delta \mathrm{E}_{\mathrm{int}}=\Delta \frac{1}{2} \sum_{\mathrm{i}=1}^{17}\left(\mathrm{~m}_{\mathrm{s}} \mathrm{V}_{\mathrm{s}}^{2}+\mathrm{I}_{\mathrm{s}} \omega_{\mathrm{s}}^{2}\right)
$$

Where "s" represents a segment, " $\mathrm{m}_{\mathrm{s}}$ " is the mass of the segment $(\mathrm{kg})$ considered and "I $\mathrm{s}_{\mathrm{s}}$ " is the moment of inertia of the segment $\left(\mathrm{kg} \cdot \mathrm{m}^{2}\right)$. "V $\mathrm{V}$ " is the velocity of the centre of mass of the segment $\left(\mathrm{m}_{\mathrm{s}} \mathrm{s}^{-1}\right)$ with respect to the referential linked to the CM. " $\omega_{\mathrm{s}}$ " is the angular velocities of the centre of mass of the segment $\left(\mathrm{rad} . \mathrm{s}^{-1}\right)$ with respect to the referential linked to the $\mathrm{CM}$ of the segment. Kinetic, potential and internal mechanical cost expressed in $\mathrm{J}_{\mathrm{kg}} \mathrm{kg}^{-1} \cdot \mathrm{m}^{-1}\left(\mathrm{C}_{\mathrm{ke}}, \mathrm{C}_{\mathrm{pe}}, \mathrm{C}_{\mathrm{int}}\right)$ are equal to the positive variation of $\Delta \mathrm{E}_{\mathrm{ke}}, \Delta \mathrm{E}_{\mathrm{pe}}$ and $\Delta \mathrm{E}_{\mathrm{int}}$ divided by the mass of the subject and his step amplitude. These parameters were measured during the steady state of $\dot{\mathrm{VO}}_{2}$, at the end of the exhaustive run.

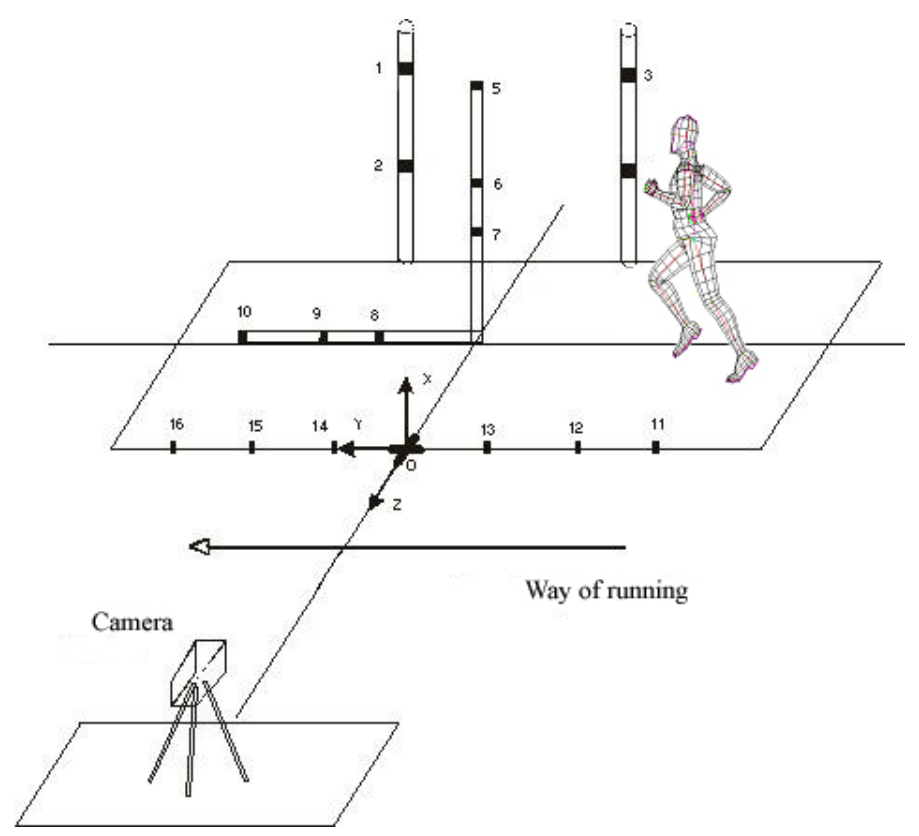

Fig. 1: Representation of space calibration and of the field of the camera 

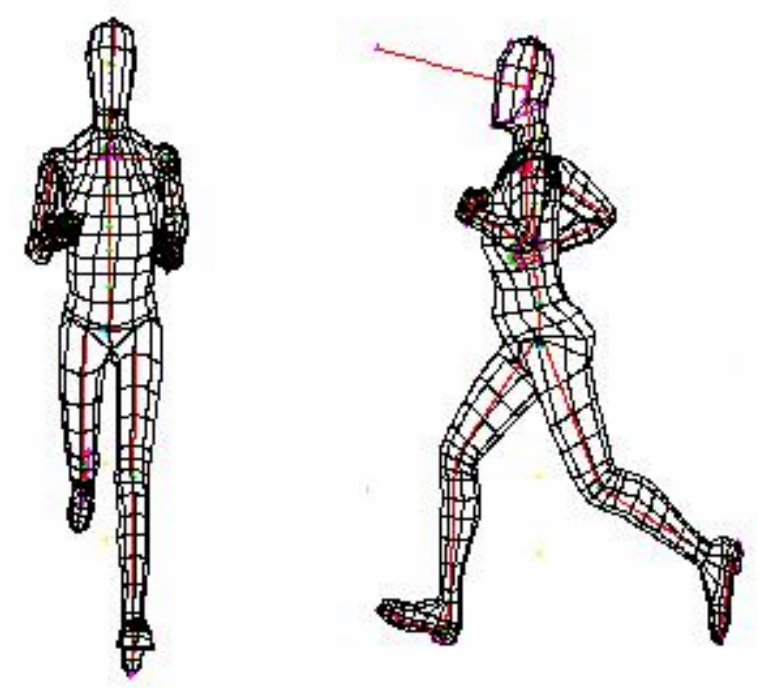

Fig. 2: MAN3D human manikin representation.

Paragraph Number 12

\section{Statistics}

An ANOVA permitted to compare $\mathrm{C}_{\mathrm{pe}}, \mathrm{C}_{\mathrm{ke}}, \mathrm{C}_{\mathrm{int}}, \mathrm{C}, \dot{\mathrm{V}} \mathrm{O}_{2 \max }, \mathrm{v} \dot{\mathrm{V}} \mathrm{O}_{2 \max }$, the running test speed, the weight and the height of the different populations. A post hoc test was used (PLSD Fischer test) to identify differences between the groups. Pearson's correlation coefficients were used to evaluate the relationships among variables.

\section{RESULTS}

Paragraph Number 10

Characteristics of the highly, well and non trained runners 
$\dot{\mathrm{V}} \mathrm{O}_{2 \max }$ and $\mathrm{v} \dot{\mathrm{V}} \mathrm{O}_{2 \max }$ were significantly greater in trained subjects. Indeed, both parameters were greater for highly trained runners compared to well trained runners or compared to non-trained runners (table 1).

The speed of the constant load exercise was not significantly different between the groups $(\mathrm{p}=0.33)$. The different measures obtained from the different populations, during the constant load exercise $\left(\mathrm{C}_{\mathrm{pe}}, \mathrm{C}_{\mathrm{ke}}, \mathrm{C}_{\mathrm{int}}\right.$ and $\left.\mathrm{C}\right)$, were performed for similar running speeds (table 1).

Paragraph Number 13

Effect of the endurance training status on $C, C_{p e}, C_{k e}, C_{i n t}$ and the step rate.

The metabolic cost of running reported in table 2 is the "gross" value, including the $\mathrm{O}_{2}$ consumption at rest. The less trained runners do not consume more energy than the highly trained runners. Indeed, in order to move forward at the same running speed (table 2) the highly trained runners present a same $\mathrm{C}$ as well-trained, or non-trained runners. Moreover, when the energetic equivalent of lactate (EEL) is added to $\mathrm{C}$ there is also no difference between the groups. 
Table 2: Effects of the endurance training status on the gross energetic cost $(\mathrm{C})$, the gross energetic cost plus the energetic equivalent of lactate $(C+E E L)$, the step rate (SR), the step length (SL), the kinetic, potential and internal mechanical costs $\left(\mathrm{C}_{\mathrm{ke}}\right.$, $\mathrm{C}_{\mathrm{pe}}, \mathrm{C}_{\mathrm{int}}$, respectively).

\begin{tabular}{|c|c|c|c|c|}
\hline & $\begin{array}{c}\text { Highly trained } \\
( \pm S D)\end{array}$ & $\begin{array}{l}\text { Well trained } \\
\quad( \pm S D)\end{array}$ & $\begin{array}{c}\text { Non trained } \\
( \pm S D)\end{array}$ & ANOVA \\
\hline$C_{k e}\left(J \cdot \mathrm{kg}^{-1} \cdot \mathrm{m}^{-1}\right)$ & $1.54 \pm 0.70$ & $1.41 \pm 0.40$ & $1.43 \pm 0.33$ & 0.89 \\
\hline$C_{p e}\left(J \cdot \mathrm{kg}^{-1} \cdot \mathrm{m}^{-1}\right)$ & $0.43 \pm 0.07$ & $0.45 \pm 0.05$ & $0.54 \pm 0.08^{\dagger \S}$ & 0.02 \\
\hline$C_{\text {int }}\left(J \cdot \mathrm{kg}^{-1} \cdot \mathrm{m}^{-1}\right)$ & $0.80 \pm 0.12$ & $0.60 \pm 0.09^{\dagger}$ & $0.59 \pm 0.10^{\dagger}$ & $\leq 0.01$ \\
\hline$C\left(J \cdot \mathrm{kg}^{-1} \cdot \mathrm{m}^{-1}\right)$ & $4.46 \pm 0.38$ & $4.33 \pm 0.32$ & $4.46 \pm 0.46$ & 0.75 \\
\hline $\begin{array}{c}C+E E L \\
\left(J . \mathrm{kg}^{-1} \cdot \mathrm{m}^{-1}\right)\end{array}$ & $4.56 \pm 0.39$ & $4.75 \pm 0.32$ & $4.89 \pm 0.44$ & 0.30 \\
\hline$R$ & $0.94 \pm 0.08$ & $1.00 \pm 0.03$ & $1.06 \pm 0.05^{\dagger}$ & $<0.01$ \\
\hline$S R(H z)$ & $3.21 \pm 0.22$ & $3.01 \pm 0.11^{\dagger}$ & $2.96 \pm 0.21^{\dagger}$ & 0.05 \\
\hline$S L(m)$ & $1.52 \pm 0.14$ & $1.66 \pm 0.08^{\dagger}$ & $1.58 \pm 0.12$ & 0.09 \\
\hline
\end{tabular}

${ }^{\dagger}$ Significantly different from highly trained runner $(\mathrm{p} \leq 0.05)$.

${ }^{\S}$ Significantly different from well trained runner $(\mathrm{p} \leq 0.05)$.

\section{Paragraph Number 14}

$\mathrm{C}_{\mathrm{pe}}$ was significantly lower in highly and well trained runners compared to non trained runners $(20 \%)$. Inversely, the step rate (SR) was significantly higher in highly trained runners compared to well and non trained runners. Moreover, there was an inverse correlation between $\mathrm{SR}$ and $\mathrm{C}_{\mathrm{pe}}$ or the vertical displacement of the centre of mass $(\mathrm{CM})($ respectively $\mathrm{r}=-0.63 ; \mathrm{p}=0.001$ and $\mathrm{r}=-0.81 ; \mathrm{p} \leq 0.0001$ ). Figure 3 shows that runners who present the greatest vertical displacement of the $\mathrm{CM}$ also possess the weakest limb displacement speed around the CM. Indeed, the vertical displacement of the $\mathrm{CM}$ for the different group is $6.7 \pm 0.9 \mathrm{~cm}$ for the highly trained runners compared 
to $7.7 \pm 0.7 \mathrm{~cm}$ for the well trained runners, and $8.3 \pm 1.3 \mathrm{~cm}$ for the non trained runners $(\mathrm{p}=0.02)$.

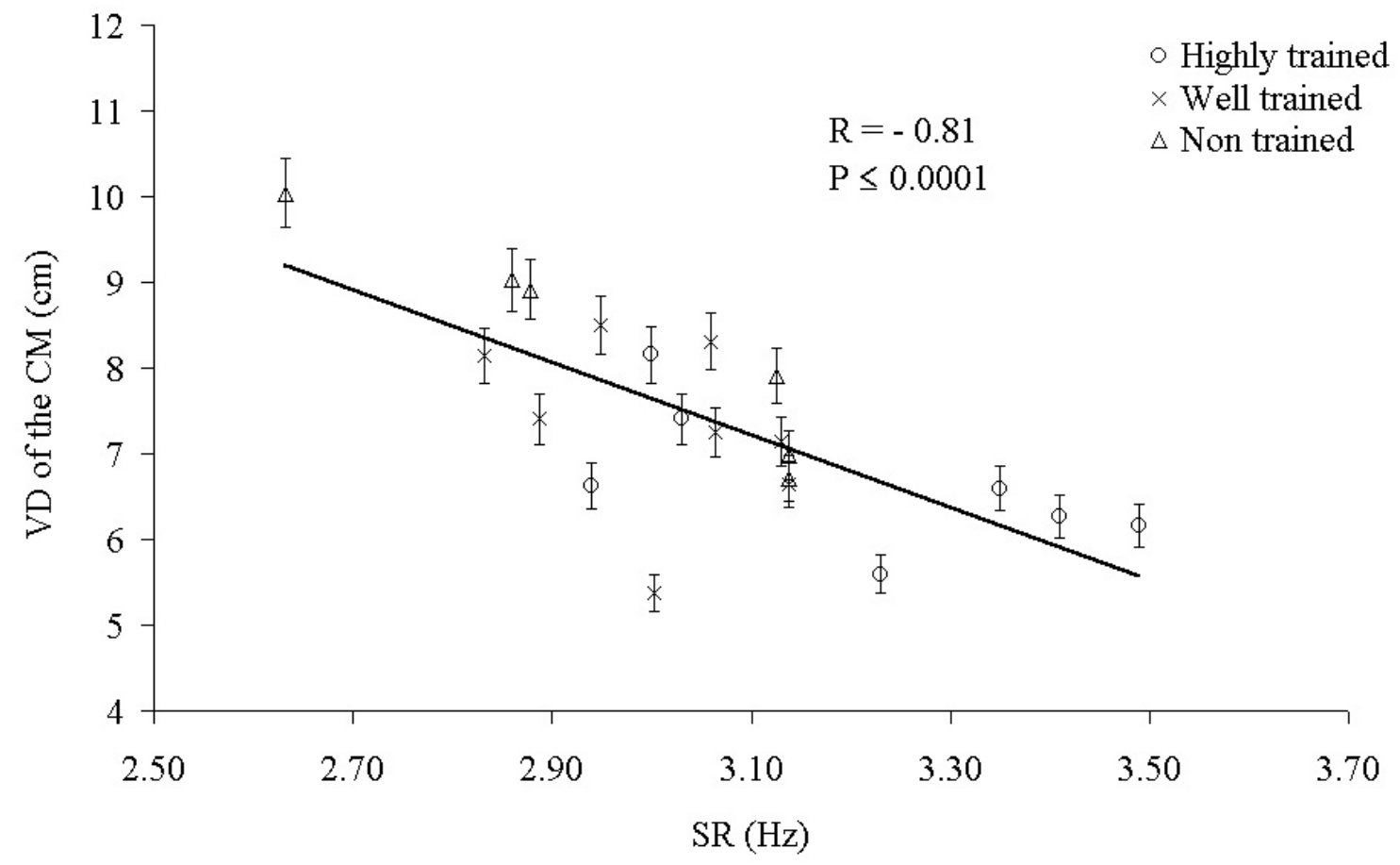

Fig. 3 : Correlation between the vertical displacement of the centre of mass (VD of the $\mathrm{CM}$ ) and the step rate (SR). The verticals bars represent the standard error of measure.

\section{Paragraph Number 15}

$\mathrm{C}_{\text {int }}$ was also significantly higher in highly trained runners: $30 \%$ greater in comparison with well trained runners and $37 \%$ greater in comparison with non trained runners. $\mathrm{C}_{\mathrm{int}}$ was correlated with the vertical displacement of the $\mathrm{CM}(\mathrm{r}=-0.46 ; \mathrm{p}=0.03)$, but not with SR $(r=0.41 ; p=0.07)$ or with $C_{p e}(r=-0.32 ; p=0.16)$.

\section{Paragraph Number 16}

The running speed was similar in all the runners, therefore $C_{k e}$ was not significantly different in the three populations of different training status $(\mathrm{p}=0.89)$. 
Paragraph Number 17

Relationship between $C, C_{k e}, C_{p e}, C_{i n t}, S R$ and $\dot{V} O_{2 \max }$.

Although $\mathrm{C}_{\mathrm{pe}}$ and $\mathrm{C}_{\mathrm{int}}$ were significantly different according to the training status of the runners, there was no correlation between $\mathrm{C}$ and $\mathrm{C}_{\mathrm{pe}}$ or $\mathrm{C}_{\mathrm{int}}$ (figure 4). The correlation coefficients were near $r=0.05$ and $p=0.83$ for $\mathrm{C}_{\mathrm{ke}}, \mathrm{r}=-0.13$ and $\mathrm{p}=0.58$ for $\mathrm{C}_{\mathrm{pe}}$ and $\mathrm{r}=0.41$, and $\mathrm{p}=0.06$ for $\mathrm{C}_{\mathrm{int}}$. Furthermore, there was no correlation between the SR and $\mathrm{C}(\mathrm{r}=0.15 ; \mathrm{p}=0.53)$. These results showed that the interindividual variability of $\mathrm{C}$ can not be explained by biomechanical parameters such as $\mathrm{SR}, \mathrm{C}_{\mathrm{pe}}, \mathrm{C}_{\mathrm{ke}}$ or $\mathrm{C}_{\mathrm{int}}$. However, $\mathrm{SR}, \mathrm{C}_{\mathrm{pe}}$ and $\mathrm{C}_{\mathrm{int}}$ were significantly correlated with $\dot{\mathrm{VO}}_{2 \max }($ respectively $\mathrm{r}=0.58 ; \mathrm{p}=0.007 ; \mathrm{r}=-0.73 ; \mathrm{p}=0.0001 ; \mathrm{r}=0.60 ; \mathrm{p}=0.004)$.

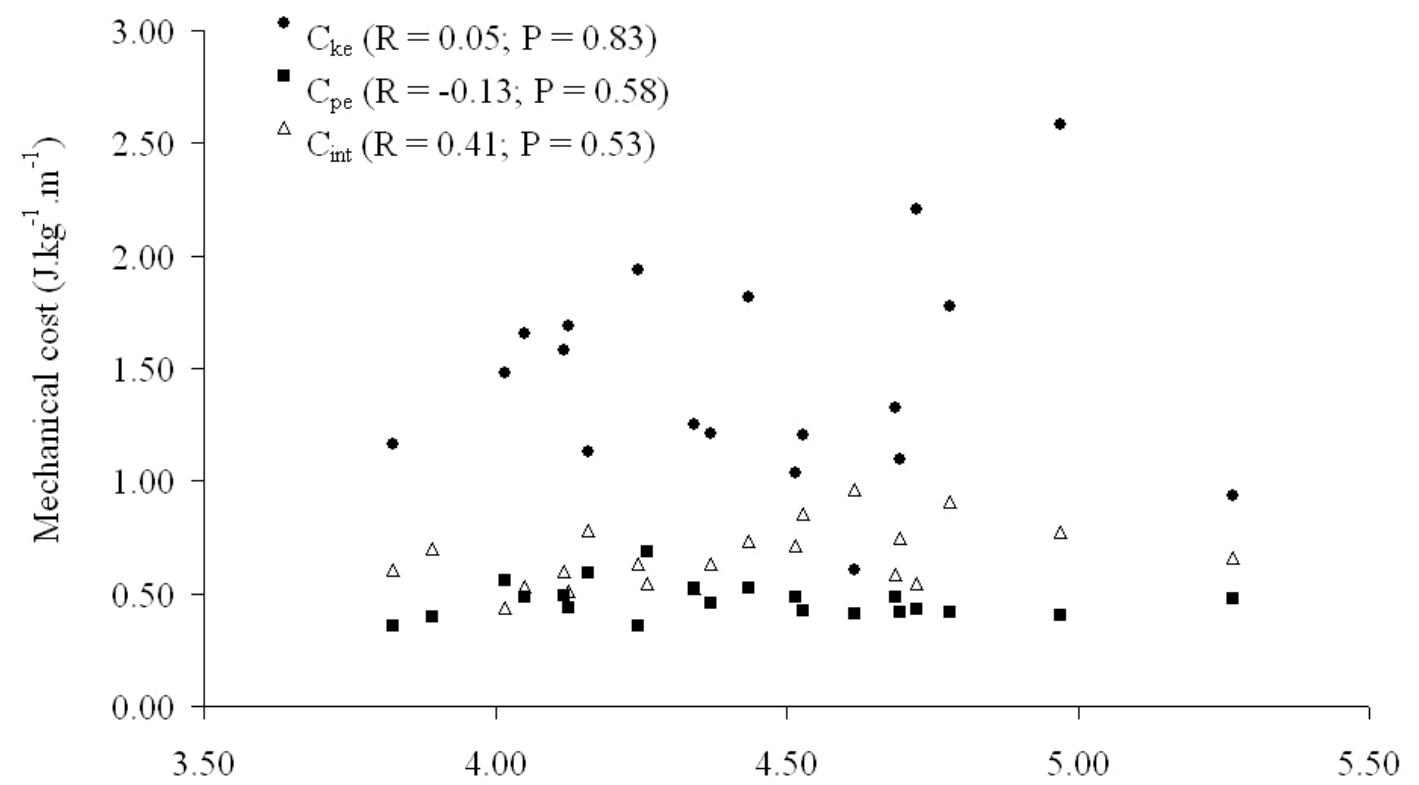

Energy cost $\left(\mathrm{J}_{\mathrm{kg}} \mathrm{kg}^{-1} \cdot \mathrm{m}^{-1}\right)$

Fig. 4: Relationship between the energy cost of running $(\mathrm{C})$, the kinetic mechanical $\operatorname{cost}\left(\mathrm{C}_{\mathrm{ke}}\right)$, the potential mechanical cost $\left(\mathrm{C}_{\mathrm{pe}}\right)$ and the internal mechanical cost $\left(\mathrm{C}_{\mathrm{int}}\right)$. 


\section{DISCUSSION}

\section{Paragraph Number 18}

The purpose of this work was to test the hypothesis that the lower energy cost in highly trained runners is associated with a lower mechanical cost. To test this hypothesis, $\mathrm{C}, \mathrm{C}_{\mathrm{ke}}, \mathrm{C}_{\mathrm{pe}}$ and $\mathrm{C}_{\mathrm{int}}$ were measured in runners who differ in training status. The results showed that contrary to our hypothesis, the energy cost of running was not different for runners with different training status. However, the mechanical cost is different for runners with different training status. Indeed, the mechanical cost associated to the vertical movements of the centre of mass $\left(\mathrm{C}_{\mathrm{pe}}\right)$ was smaller in highly trained runners. Inversely, the mechanical cost associated with the movement of the segments around the centre of mass $\left(\mathrm{C}_{\text {int }}\right)$ and the step rate $(\mathrm{SR})$ were greater.

\section{Paragraph Number 19}

There was no difference in the energy cost of running between the three groups, whereas such a difference would be expected and has been demonstrated in previous studies $(5,31,33)$. Numerous mechanisms such as a decrease in the ventilation, an optimisation of the neuromuscular recruitment, an improvement in the transport of oxygen by the blood, the use of this oxygen by the active muscles or the increase of the muscular elasticity $(12,30)$ could be at the origin of the improvement in the energy cost with training. However, mechanisms associated with this decrease are not well known and numerous studies do not report any change after a period of training $(13,25,31,32,36)$. Daniels and Daniels (12) have shown that for intensities typically used in races up through the marathon, no differences exist in $\mathrm{C}$ within the range of most intensities (80-100\% of $\dot{\mathrm{VO}}_{2 \max }$ ). In the present study, the range of intensities was comprised within $80 \%$ and $97 \%$ of $\mathrm{v} \dot{\mathrm{VO}}_{2 \max }$. Therefore, the lack of difference in $\mathrm{C}$ among runners of different training 
levels may be associated with the fact that $\mathrm{C}$ is measured for speeds upper to speeds typically used during a marathon race.

Paragraph Number 20

Following this hypothesis, the present results show that the mechanical cost of the vertical movements of the $\mathrm{CM}\left(\mathrm{C}_{\mathrm{pe}}\right)$ is smaller in highly trained runners. This result is in accordance with the generally acknowledged principle which states that smaller verticals oscillations of the body centre of mass are associated with a high level of training $(28,37)$. However, there was no relationship observed between $\mathrm{C}_{\mathrm{pe}}$ and $\mathrm{C}$ (figure 4). According to the training status, the variation in $\mathrm{C}_{\mathrm{pe}}$ is not associated with the variation in C. Similarly, the kinetic mechanical cost $\left(\mathrm{C}_{\mathrm{ke}}\right)$ or the mechanical cost of the movements of the segments around the centre of mass $\left(\mathrm{C}_{\mathrm{int}}\right)$ were not correlated with C (figure 4). These results agree with numerous studies which have demonstrated that the relationships between $\mathrm{C}$ and the mechanical cost are both weak and inconsistent $(11,28,37)$. The mechanical cost reflects a global and indirect expression of the muscular effort which explains why a low correlation is observed between $\mathrm{C}$ and the mechanical cost. Other mechanical parameters should be correlated with $\mathrm{C}$. Indeed, it has been shown that less economical runners possess a more compliant running style during ground contact $(11,24)$.

Paragraph Number 21

Collectively, the results reported here, do not confirm our primary hypothesis and suggest that the mechanical cost $\left(\mathrm{C}_{\mathrm{pe}}\right.$ and $\left.\mathrm{C}_{\text {int }}\right)$ is not correlate with $\mathrm{C}$ but with $\dot{\mathrm{VO}}_{2 \max }$. The mechanism that explains the modifications of the mechanical parameters ( $\mathrm{SR}, \mathrm{C}_{\mathrm{pe}}$ and $\mathrm{C}_{\mathrm{int}}$ ) is in relation with the level of training of the runners rather than their energy cost. However, this mechanism has to be elucidated.

Paragraph Number 22 
If humans are self-optimizing machines, the minimal cost, being an optimally criterion, may be identified that governs the kinematic and kinetic detail of the performance. For example, it has been shown that adult and children tend to walk or run at frequencies that are determined by the oxygen cost (10). However, it is unlikely that the metabolic cost is the only optimality criteria adopted for human activity. The potential for injury may also result in the development of optimal criteria. Farley and Taylor (19) reported that horses naturally switch from a trot to a gallop actually increasing their metabolic cost but reducing the peak of forces on the muscles, tendons and bones. They suggest that this mechanism reduces the chance of injury for the horse. During human running, the body is subjected to high impact loads during the initial portion of the support phase of the stride. These impacts have magnitudes up to 2.3 times body weight (BW) with an impact load rate of 113 BW.s ${ }^{-1}$ (29). Increases in impact shock can result from an increase in running speed (21), from running downhill (22), from an increase in stride length $(15,23)$ or fatigue $(35)$. It would appear therefore, that impact shock attenuation may be an important factor on which individuals optimise. In a same way, Zamparo et al. (38) have recently demonstrated that the self selected speed of running depends not only on cardiovascular factors, but also on biomechanical factors.

\section{Paragraph Number 23}

The running style of the highly trained runners may be associated with the same selfoptimizing mechanism which contributes to reducing the impact loads during the initial portion of the support phase of the stride. Indeed, this style is characterised by a high SR and a low $\mathrm{C}_{\mathrm{pe}}$ and a low vertical displacement of the CM. Moreover, the figure 3 shows that the vertical displacement of the CM is inversely correlated to SR. This inverse relationship shows that a high stride rate is linked to a smaller vertical 
displacement of the CM. During the flight phase, the $\mathrm{CM}$ of highly trained runners may reach a lower height (table 2), which decreases the impact shock when the foot hits the ground. This result is in accordance with the results of Farley and Gonzales (20) which show that at higher step rate, the initial vertical force peak is absent and that the vertical force peak is decreased. This style of running may be associated with the training mode of the runners. Indeed, the nature of the adaptive responses to training is specific to the training stimulus. Highly trained runners cover very long distances during training session, and perform a very high number of strides (more than $20 \mathrm{~km}^{-\mathrm{day}^{-1}}$; (6)) compared to the other populations studied. For example, running $32 \mathrm{~km} . \mathrm{week}^{-1}$ will produce over 1.3 million impacts to the body over a period of one year (16). More frequent impacts will place greater stress on the muscles, tendons and bones resulting in an increased risk of injury and degenerative disease (15). Therefore, to attenuate this risk, mechanical adjustments such as a decrease in the vertical oscillation of the $\mathrm{CM}$ may take place with training. Following this hypothesis, the modification of the mechanics of running with the training status does not have any relationship with the energy cost of running $(\mathrm{C})$.

\section{Paragraph Number 24}

To conclude, highly trained runners did not display a lower C. However, $\mathrm{C}_{\mathrm{pe}}$ was $20 \%$ lower and $\mathrm{C}_{\text {int }}$ was $30 \%$ greater in highly trained runners. The endurance training leads to an increase of $\mathrm{C}_{\mathrm{int}}$ and a decrease in $\mathrm{C}_{\mathrm{pe}}$ without any modification of $\mathrm{C}$. These mechanical adjustments may be associated with the same self-optimizing mechanisms which contribute to reduce the impact loads during the initial portion of the support phase of the stride.

The authors gratefully acknowledge the Fédération Française de Ski and Michel Tavernier for their assistance during the experiment. 


\section{References.}

1. Bailey, S., S. Messier. Variation in stride length and running economy in male novice runners subsequent to a seven-week training program. Int. J. Sports. Med. 12: 299304, 1991.

2. Barstow, T., P. Mole. Linear and nonlinear characteristics of oxygen uptake kinetics during heavy exercise. J. Appl. Physiol. 71: 2099-2106, 1991.

3. Bernard, O., F. Maddio, S. Ouattara, C. Jimenez, A. Charpenet, B. Melin, and J. Bittel. Influence of the oxygen uptake slow component on the aerobic energy cost of highintensity submaximal treadmill running in humans. Eur. J. Appl. Physiol. 78: 578-585, 1998.

4. Billat, V., R. Richard, V., Binsse, J.P., Koralsztein, and P., Haouzi. The V(O2) slow component for severe exercise depends on type of exercise and is not correlated with time to fatigue. J. Appl. Physiol. 85: 2118-24, 1998.

5. Billat, V., B. Flechet, B. Petit, G. Muriaux, and J.P. Koralsztein. Interval training at $\dot{\mathrm{VO}}_{2 \max }$ effects on aerobic performance and overtraining markers. Med. Sci. Sports Exerc. 31: 156-163, 1999.

6. Billat, V., A. Demarle, J. Slawinski, M. Paiva, and J.P. Koralsztein. Physical training characteristics of top-class marathon runners. Med. Sci. Sports Exerc. 33: 2089-2097, 2001. 
7. Borrani, F., R. Candau, G. Millet, S. Perrey, J. Fuchslocher, and J. Rouillon. Is the $\dot{\mathrm{VO}}_{2}$ slow component dependent on progressive recruitment of fast-twitch fibers in trained runners? J. Appl. Physiol. 90: 2212-20, 2001.

8. Bourdin, M., A. Belli, L. Arsac, C. Bosco, J.R. Lacour. Effect of vertical loading on energy cost and kinematics of running in trained male subjects. J. Appl. Physiol. 79: 2078-85, 1995.

9. Candau, R., A. Belli, G, Millet, D, Georges, B, Barbier, J.D. Rouillon. Energy cost and running mechanics during a treadmill run to voluntary exhaustion in humans. Eur. J. Appl. Physiol. Occup. Physiol. 77: 479-85, 1998.

10. Cavanagh, P.R., K.R. Williams. The effect of stride length variation on oxygen uptake during distance running. Med. Sci. Sports Exerc. 14: 30-5, 1982.

11. Dalleau, G., A. Belli, M. Bourdin, J.R. Lacour. The spring-mass model and the energy cost of treadmill running. Eur. J. Appl. Physiol. Occup. Physiol. 77: 257-63, 1998.

12. Daniels, J. Physiological characteristics of champion male athletes. Res. Q. Exercise Sport 45: 342-348, 1974.

13. Daniels, J., R. Yarbrough, C. Foster. Changes in VO2 max and running performance with training. Eur. J. Appl. Physiol. Occup. Physiol. 39: 249-54, 1978. 
14. Daniels, J. and N. Daniels. Running economy of elite male and elite female runners. Med. Sports Sci. Exerc. 24: 483-489, 1992

15. Derrick, T., J. Hamill, G. Caldwell. Energy absorption of impacts during running at various stride lengths. Med. Sports Sci. Exerc. 30: 128-135, 1998.

16. Derrick, T., F. Dereu, and S. McLean. Impacts and kinematic adjustments during an exhaustive run. Med. Sports Sci. Exerc. 34: 998-1002, 2002.

17. di Prampero, P. Energetics of muscular exercise. Rev. Physiol. Biochem. Pharmacol. 89: 143-222, 1981.

18. di Prampero, P. The energy cost of human locomotion on land and in water. Int. J. Sports Med. 7: 55-72, 1986.

19. Farley, C., C. Taylor. A mechanical trigger for the trot-gallop transition in horse. Science 253: 306-308, 1991.

20. Farley, C., O. Gonzalez. Leg stiffness and stride frequency in human running. $J$. Biomech. 29: 181-6, 1996.

21. Hamill, J., B. Bates, K. Knutzen, and J. Sawhill. Variation in ground reaction force parameters at different running speeds. Hum. Mov. Sci. 2: 47-56, 1983. 
22. Hamill, C., T. Clarke, E. Frederick, L. Goodyear, and E. Howley. Effect of grade running on kinematics and impact force. Med. Sci. Sports Exerc. 16: S85, 1984.

23. Hamill, J., T. Derrick, and K. Holt. Shock attenuation and stride frequency during running. Hum. Mov. Sci. 14: 45-60, 1995.

24. Heise, G., P. Martin. "Leg spring" characteristics and the aerobic demand of running. Med. Sci. Sports Exerc. 30: 750-4, 1998.

25. Lake, M., and Cavanagh P. Six weeks of training does not change running mechanics or improve running economy. Med. Sci. Sports Exerc. 7 : 860-869, 1996.

26. McFarlane, D. Automated metabolic gas analysis system. Sports Med. 31: 841-861, 2001.

27. McMahon, T., G. Valiant, and E. Frederick. Grouncho running. J. Appl. Physiol. 62: 2326-2337, 1987.

28. Morgan, D., P. Martin, and G. Krahenbuhl. Factors affecting running economy. Sports Med. 7: 310-30, 1989.

29. Munro, C., D. Miller, and A. Fuglevand. Ground reaction forces in running: a reexamination. J. Biomech. 20: 147-155, 1987. 
30. Paavolainen L., K. Kakkinen, I. Hamalainen, A. Nummela, H. Rusko. Explosive strength training improves $5-\mathrm{km}$ running time by improving running economy and muscle power. J. Appl. Physiol. 86: 1527-1533, 1999.

31. Petray, C., and G. Krahenbuhl. Running training instruction on running technique, and running economy in 10 year-old males. Res. Q. Exercise Sport. 56 : 251-255, 1985.

32. Slawinski, J., A. Demarle, J.P. Koralsztein, and V. Billat. Effect of supra-lactate threshold training on the relationship between mechanical stride descriptors and aerobic energy cost in trained runners. Arch. Physiol. Biochem. 109: 110-116, 2001.

33. Smith, T., L. McNaughton, and K. Marshall. Effects of 4-week training using Vmax/Tmax on $\dot{\mathrm{V} O} 2 \max$ and performance in athletes. Med. Sci. Sports Exerc. 31: 892896, 1999.

34. Tavernier, M., P. Cosserat, A. Emmendoerffer, A. Ruby, J. Lavest, M. Dhome, and J.P. Verriest. A 3D motion analysis system using a numerical human model. In Proceedings of the International Society of Biomechanics Congress, Tokyo, Vol 19, pp. 406, 1997.

35. Verbitsky, O., J. Mizrahi, J. Voloshin, J. Treiger, and E. Isakov. Shock transmission and fatigue in human running. J. Appl. Biomech. 14: 300-311, 1998.

36. Wilcox, A., and R. Bulbulian. Change in running economy relative to $\dot{\mathrm{VO}}_{2 \max }$ during a cross-country season. J. Sports Med. Phys. Fitness. 24: 321-326, 1984. 
37. Williams, K., P. Cavanagh. Relationship between distance running mechanics, running economy, and performance. J. Appl. Physiol. 63: 1236-1245, 1987.

38. Zamparo, P., R. Perini, C. Peano, P.E. di Prampero. The self selected speed of running in recreational long distance runners. Int. J. Sports Med. 22: 598-604, 2001 